\title{
ВЛИЯНИЕ ЦЕННЫХ КОМПОНЕНТОВ БИОМАССЫ CHLORELLA SOROKINIANA НА ЖИЗНЕДЕЯТЕЛЬНОСТЬ ДРОЖЖЕЙ SACCHAROMYCES CEREVISIAE
}

\author{
T.A. Kuznetsova, O.B. Ivanchenko
}

\section{THE INFLUENCE OF VALUABLE COMPONENTS OF CHLORELLA SOROKINIANA BIOMASS ON THE VITALITY OF SACCHAROMYCES CEREVISIAE YEAST}

Кузнецова T.A. - канд. биол. наук, доц. Высшей школы биотехнологии и пищевых производств Санкт-Петербургского политехнического университета Петра Великого, г. Санкт-Петербург.

E-mail: kuznetsova.ta1@spbstu.ru

Иванченко О.Б. - канд. биол. наук, доц. Высшей школы биотехнологии и пищевых производств Санкт-Петербургского политехнического университета Петра Великого, г. Санкт-Петербург.

E-mail: obivanchenko@yandex.ru

Цель исследования - изучение влияния дезинтегрированной биомассы микроводоросли Chlorella sorokiniana на активность дрожжей при брожении. Материал исследования - воздушно-сухая биомасса, полученная при культивировании прекультуры C. sorokiniana (штамм 211-8k), сухие хлебопекарные дрожжи $S$. cerevisiae. Необходимым технологическим этапом является предварительная подготовка биомассы C. sorokiniana путем дезинтеграции. Наиболее часто используют способы дезинтеграции ультразвуковой, микроволновой дезинтеграции и с помощью высокочастотного гомогенизатора. Дезинтегрированная биомасса была внесена в питательную среду в количестве 20 мг\%. Подготовленную водную суспензию с биомассой хлореллы использовали в качестве дополнительного компонента питательной среды на стадии внесения чистой культуры дрожжей. В качестве питательной среды использовали квасное сусло. В 100 мл квасного сусла вносили 10 мл суспензии с содержанием биомассы хлореллы 20 ме. Масса внесенных лиофилизированных дрожжей составляла 0,1 г/100 мл питательной среды. Брожение проводили в течение 6 ч при температуре $32 \pm 2{ }^{\circ} \mathrm{C}$. Содержание спирта, видимую степень сбраживания определяли с помощью анализатора «Колос-2». Концентрацию дрожжевых клеток в суспензии определяли путем
Kuznetsova T.A. - Cand. Biol. Sci., Assoc. Prof., Higher School of Biotechnology and Food Productions, St. Petersburg Polytechnic University named after Peter the Great, St. Petersburg.

E-mail: kuznetsova.ta1@spbstu.ru

Ivanchenko O.B. - Cand. Biol. Sci., Assoc. Prof., Higher School of Biotechnology and Food Productions, St. Petersburg Polytechnic University named after Peter the Great, St. Petersburg.

E-mail: obivanchenko@yandex.ru

подсчета в камере Горяева. Анализируемыми показателями брожения стали интенсивность спиртообразования, видимая степень сбраживания, интенсивность роста популяции дрожжей, а также наиболее инфформативные морфоофизиологические показатели. Наиболее эфьфоктивным вариантом дезинтеграции по сравнению с контрольным вариантом (без добавки водорослей) стало использование микроволновой дезинтеграции: наблюдается увеличение спиртообразующей способности (на 43,5 $\%)$, видимой степени сбраживания (на 39,2 \%) и количества дрожжевых клеток в популяции (на 31,0 \%). Ультразвуковая и механическая дезинтеграция биомассы микроводоросли менее эфффективны. Таким образом, использование микроводорослей C. sorokiniana как источника ценных компонентов - перспективный путь активирования метаболизма дрожжей $S$. cerevisiae, который требует дополнительных исследований в разработке технологии предварительной дезинтеграции и комплексной переработки вносимой биомассы.

Ключевые слова: Saccharomyces cerevisiae, Chlorella sorokiniana, дезинтеграция биомассы, активирование метаболизма, биодоступность, биологически активнье вещества.

The research objective was studying the influence of disintegrated biomass of microalga of Chlo- 
rella sorokiniana on the activity of yeast at fermentation. The research material was air and dry biomass received at cultivation of prekultura of $S$. of sorokiniana (strain 211-8k), dry S. cerevisiae baker's yeast. Necessary technological stage was preliminary preparation of sorokiniana biomass $C$. by disintegration. The ways of disintegration of ultrasonic, microwave disintegration and by means of high-frequency homogenizer are most often used. Disintegrated biomass was brought in a nutrient medium in the number of $20 \mathrm{mg} \%$. Prepared water suspension with biomass of hlorella was used as an additional component of a nutrient medium at the stage of introduction of pure culture of yeast. As nutrient medium kvass wort was used. $10 \mathrm{ml}$ of suspension with the content of biomass of hlorella of $20 \mathrm{mg}$ was brought in $100 \mathrm{ml}$ of kvass wort. The mass of brought lyophilized yeast made $0.1 \mathrm{~g} / 100$ $\mathrm{ml}$ of nutrient medium. Fermentation was carried out during 6 hours at the temperature of $32 \pm 2{ }^{\circ} \mathrm{C}$. The content of alcohol and visible degree of fermentation were determined by Kolos-2 analyzer. The concentration of barmy cells in suspension was defined by calculation in Goryaev's chamber. The intensity of alcohol formation, visible degree of fermentation, the intensity of growth of yeast population and also the most informative morphophysical indicators became analyzed fermentation indicators. Using microwave disintegration became the most effective option of disintegration in comparison with control option (without additive of seaweed): the increase in alcohol forming ability (for $43.5 \%$ ), visible degree of fermentation (for $39.2 \%$ ) and the quantities of barmy cells in the population was observed (for $31.0 \%$ ). Ultrasonic and mechanical disintegration of biomass of microalga were less effective. Thus, using microseaweed of S. of sorokiniana as the source of valuable components is a perspective way of activation of metabolism of S. cerevisiae yeast which demands additional researches in the development of technology of preliminary disintegration and complex processing of introduced biomass.

Keywords: Saccharomyces cerevisiae, Chlorella sorokiniana, biomass disintegration, activation of metabolism, bioavailability, biologically active agents.

Введение. Повышение эффрективности технологических процессов на бродильных производст- вах, а также повышение качества готовой продукции является в настоящее время важным вопросом. Его решение связано с увеличением метаболической активности дрожжей-сахаромицетов. С целью регуляции обменных процессов в дрожжевой клетке сегодня широко используются препараты, способствующие стимулированию размножения и роста клеток, повышению их активности, улучшению транспорта питательных веществ, более полному сбраживанию экстрактивных веществ, увеличению устойчивости к стрессовым фракторам, включая высокие концентрации спирта, низкие температуры, микоцины и др. [1].

Большинство подкормок для дрожжей, разрешенных в РФ, производят за рубежом. Наряду с подкормками применяют различные стимуляторы, для их приготовления используют растительное сырье (в том числе гидробионты), реже сырье животного происхождения [2]. В последнее время были предложены способы активации дрожжей с применением микроводоросли Spirulina platensis [3, 4]. Активацию дрожжей проводят путем внесения водоросли в готовую питательную среду или в экспоненциальной фазе роста дрожжей в сухом измельченном виде или в виде водной суспензии. Отмечено возрастание ферментативной активности, в особенности комплекса гидролитических ферментов. Клеточная оболочка спирулины легко разрушается под действием гидролитических ферментов в отличие от клеточных оболочек эукариотических водорослей, в том числе и Chlorella [3].

Проблема доступности ценных компонентов в микроводорослях может решаться предварительной дезинтеграцией клеточных оболочек различными способами, наиболее широко используются механические способы под действием силы сдвига твердого тела (бисерная мельница, высокоскоростной гомогенизатор) или силы сдвига жидкости (гомогенизация под давлением, микрофрлюидизация) [4, 5]; также при ультразвуковой обработке и под действием электромагнитного излучения в сантиметровом диапазоне (СВЧ) [6].

C. sorokiniana - перспективный, быстро pacтущий в биореакторах вид. В сухой биомассе содержится в среднем 40 \% протеинов, 30-38 \% углеводов, 18-22 \% липидов [7]. Большой интерес представляют антиоксиданты хлорофилл (3,5 \% от сухой биомассы) [8]; каротиноиды, ко- 
торые составляют до 0,69 \% в пересчете на сухую биомассу [7]. В белке хлореллы находятся все незаменимые аминокислоты, необходимые для роста дрожжей. В 1 г массы сухого вещества водоросли содержится витамина $\mathrm{B}_{1}-2$ 18 мкг; $\mathrm{B}_{2}-21-28 ; \mathrm{B}_{6}-9 ; \mathrm{C}-1300-1500 ; \mathrm{K}-6$; PP - 110-180; E - 10-350; пантотеновой кислоты - 12-17; фролиевой кислоты - 485; биотина 0,1; лейковорина - 22 мкг [9].

Биомасса хлореллы богата хлорофиллом, в состав порфириновой группы которого входит ион магния. Магний необходим как для энергетического, так и конструктивного обмена дрожжей, так как он является кофактором многих ферментов (гексокиназа, глюкозофоссфатизомераза, перуватфросфокиназы, фоссфотрансферазы и др.) и активатором гликолиза. Магний также является активатором пируватдекарбоксилазы и необходим для спиртового брожения [10]. Ион магния участвует во многих метаболических процессах и повышает эфффективность брожения [11].

Цель исследования: изучение влияния дезинтегрированной биомассы микроводоросли Chlorella sorokiniana на активность дрожжей при брожении.

В соответствии с целью исследования поставлены задачи:

- определить показатели бродильной активности - спиртообразующую способность, экстрактивность, видимую степень сбраживания, а также интенсивность почкования дрожжевых клеток;

- определить наилучший способ дезинтеграции биомассы хлореллы, позволяющий усилить бродильную активность дрожжей (Saccharomyces cerevisiae).

Материалы и методы исследования. Для исследования была использована воздушносухая биомасса, полученная при культивировании прекультуры C. sorokiniana (штамм 211-8k) [12], сухие хлебопекарные дрожжи S. cerevisiae (производство 000 «САФ-НЕВА», г. СанктПетербург). В использованной воздушно-сухой биомасcе C. sorokiniana содержание влаги не превышало 2,5\%.

Для приготовления водной суспензии биомассу предварительно подвергали механической гомогенизации, заливали водой и подвергали различным способам дезинтеграции: механический способ заключен в измельчении биомассы с помощью высокоскоростного гомогенизатора Silent Crusher M (IKA® Werke, T25 Basic) в режиме 10000 об/мин в течение 2 мин; ультразвуковой способ заключается в воздействии на суспензию биомассы хлореллы ультразвука (40 кГц в течение 30 мин при $45^{\circ} \mathrm{C}$ ) на приборе WUC-A01H DAIHAN [13]; микроволновая дезинтеграция заключалась в воздействии на суспензию биомассы хлореллы СВЧ (с частотой 2,450 МГц, в течение 5 мин), при этом температура превышала $100{ }^{\circ} \mathrm{C}$ (микроволновая печь BBK 17MWS$781 \mathrm{M} / \mathrm{W})$. В качестве контроля использовали дрожжи без добавки дезинтегрированной биомассы хлореллы в питательную среду их культивирования.

Подготовленную водную суспензию с биомассой хлореллы использовали в качестве дополнительного компонента питательной среды на стадии внесения чистой культуры дрожжей. В качестве питательной среды использовали квасное сусло (плотность 1,030 г/мл, экстрактивность 8,5 \%), с содержанием сахаров 6 г/100 мл. В 100 мл квасного сусла вносили 10 мл суспензии с содержанием биомассы хлореллы 20 мг. Масса внесенных лиофилизированных дрожжей составляла 0,1 г/100 мл питательной среды.

Брожение проводили в течение 6 ч при температуре $32 \pm 2{ }^{\circ} \mathrm{C}$. Содержание спирта, видимую степень сбраживания определяли с помощью анализатора «Колос-2». Концентрацию дрожжевых клеток в суспензии определяли путем подсчета в камере Горяева [14].

Морфофизиологические характеристики дрожжевых клеток были определены при анализе прижизненных препаратов с помощью микроскопа «Микмед-5», микрофотографии сделаны с помощью цифровой видеокамеры для микроскопа IS-500, анализ и измерение микроскопических объектов проводились с помощью компьютерной программы Levengik. Для морфофиизологического анализа дрожжевых клеток в популяции их ранжировали на «основные», подвергшиеся репликации (по форме более округлые); «молодые» клетки, которые достигли площади проекции основных, но имели более вытянутую форму. Объем и площадь дрожжевых клеток были найдены по формулам для эллипсоида [15], для этого находили длинную и короткую ось клеток:

$$
K=\frac{S}{V}=\frac{4 \pi\left[\left(2 a^{p} b^{p}+b^{2 p}\right) / 3\right]^{1 / p}}{\frac{4}{3} \times \pi \times a \times b \times c},
$$


где К - коэфффициент формы дрожжевой клетки, мкм $^{-1} ; \mathrm{S}$ - площадь эллипса, мкм²; V - объем дрожжевой клетки, мкм; п - число $(3,1415)$, a длина большой полуоси, мкм; b - длина малой полуоси, мкм; $p=1,6075$.

Количество клеток, измеренных в популяции в каждой группе, -50.

Результаты исследования и их обсуждение. Бродильная активность дрожжей зависит от их физиологического состояния, штаммовых особенностей, спиртообразующей способности и полноценности питания дрожжей. Как показало исследование, наиболее интенсивное спиртообразование наблюдается в образце с добав- ками биомассы хлореллы, подвергшейся микроволновой (СВЧ) и механической дезинтеграции. Содержание спирта превышает контроль в среднем на 43,45 и 5,17 \% соответственно (табл. 1).

Видимая степень сбраживания - показатель, определяемый отношением видимого экстракта напитка брожения к экстрактивности начального сусла, выраженный в процентах. Этот показатель также возрастает относительно контрольного образца наиболее существенно (на 39,2 \%) в варианте с применением биомассы C. sorokiniana, подвергшейся микроволновой дезинтеграции.

\section{Физико-химические показатели брожения дрожжей при их активировании биомассой}

\begin{tabular}{|l|c|c|c|c|c|}
\hline \multirow{2}{*}{ Показатель брожения } & \multirow{2}{*}{$\begin{array}{c}\text { Квасное } \\
\text { сусло }\end{array}$} & \multirow{2}{*}{ Контроль } & \multicolumn{3}{|c|}{ Способы дезинтеграции } \\
& & биомассы хлореллы \\
\hline Экстрактивность, \% & 8,5 & $5,1 \pm 0,26$ & $4,9 \pm 0,25$ & $5,2 \pm 0,30$ & $4,5 \pm 0,23$ \\
\hline Плотность, г/мл & \multirow{2}{*}{1,0301} & $\begin{array}{c}1,0170 \pm \\
0,0509\end{array}$ & $\begin{array}{c}1,0160 \pm \\
0,0508\end{array}$ & $\begin{array}{c}1,0176 \pm \\
0,0510\end{array}$ & $\begin{array}{c}1,0141 \pm \\
0,0450\end{array}$ \\
\hline Объемная доля спирта, об\% & 0 & $0,93 \pm 0,03$ & $1,07 \pm 0,04$ & $0,90 \pm 0,03$ & $1,30 \pm 0,04$ \\
\hline Видимая экстрактивность, \% & 7,9 & $4,7 \pm 0,2$ & $4,5 \pm 0,2$ & $4,8 \pm 0,2$ & $3,9 \pm 0,2$ \\
\hline Видимая степень сбраживания & 2,0 & $28,6 \pm 1,4$ & $32,5 \pm 1,6$ & $26,3 \pm 1,3$ & $39,8 \pm 1,9$ \\
\hline
\end{tabular}

Примечание: ВГ - высокочастотный гомогенизатор; УЗВ - ультразвуковое воздействие; СВЧ микроволновая дезинтеграция.

Согласно полученным данным (рис. 1), внесение биомассы хлореллы способствует интенсификации деления клеток дрожжей в варианте с микроволновой дезинтеграцией биомассы.

Максимальное число клеток на конец брожения в образце с добавлением биомассы хлореллы, подвергшейся микроволновому воздействию, на $31 \%$ превышает контроль. Положительно влияние на накопление дрожжевой биомассы добавки микроводоросли Chlorella (в концентрации 20 мг\%) отмечено в сходных исследованиях [16], однако предварительная обработка биомассы в настоящем исследовании способствует усилению эффекта.
Известно, что размер и форма клеток одного и того же штамма могут варьировать в определенных пределах в зависимости от условий культивирования. Накопление питательных веществ и фрерментов, удвоение ДНК происходит в интерфазу, почкование происходит при достижении материнской клеткой критического размера.

После отделения почки на материнской клетке образуется рубец - дочерний шрам. Репликтивное старение сопровождается утолщением клеточной стенки, клетка приобретает округлую форму в отличие от молодых клеток, имеющих более удлиненную форму $[14,15]$. 


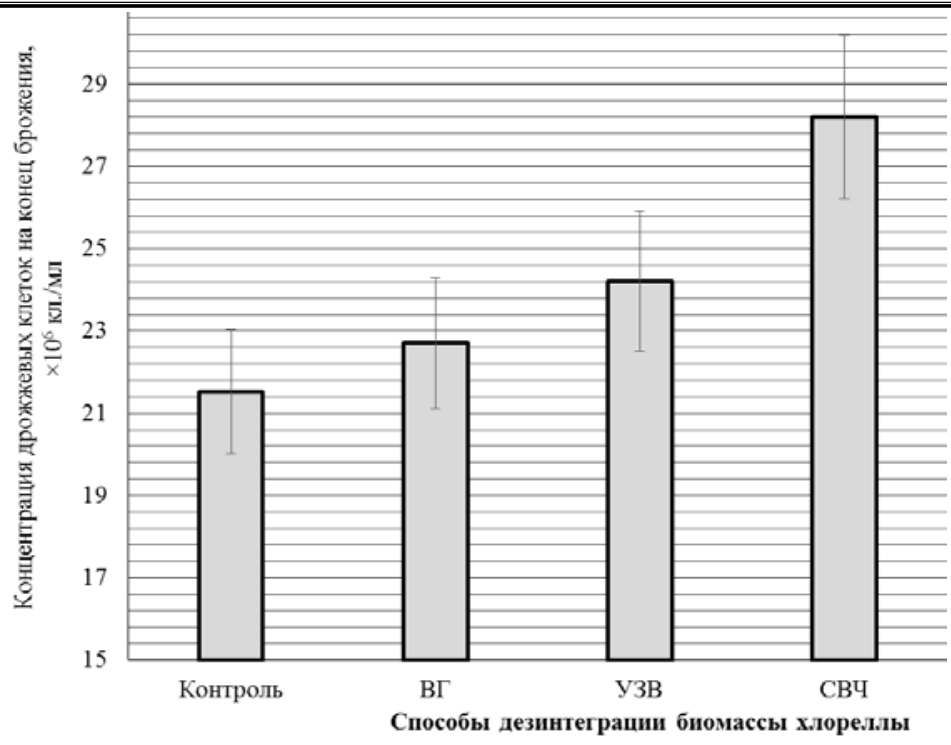

Puc. 1. Количество дрожжевых клеток в суспензии на конец брожения, х106 кл. / мл:

ВГ - высокоскоростной гомогенизатор; УЗВ - ультразвуковое воздействие; СВЧ - микроволновая дезинтеграция

Наиболее информативными морфофиизологическими показателями дрожжевых клеток является отношение площади поверхности клетки к ее объему (рис. 2).

Репликативное старение сопровождается снижением этого показателя. На рисунке 2 пред- ставлены значения коэффициента формы для популяций дрожжей в вариантах с добавками биомассы C. sorokiniana, подвергшейся различным способам дезинтеграции.

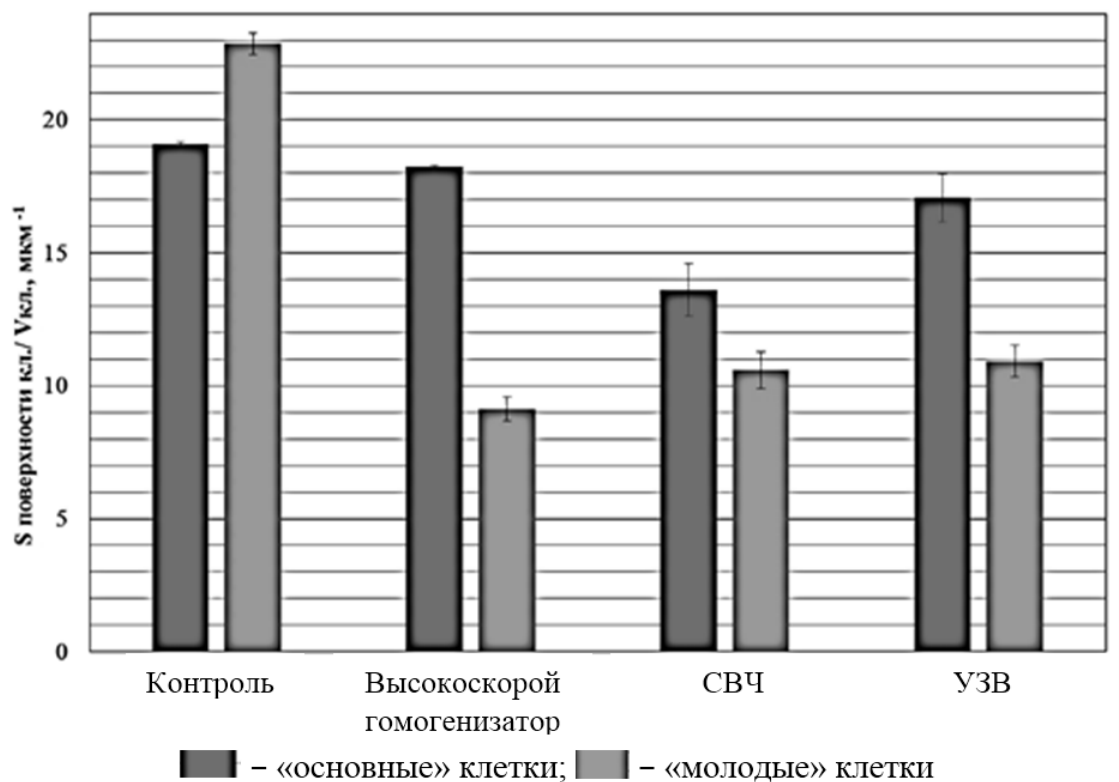

Puc. 2. Отношение площади поверхности к объему ранжированных по возрасту дрожжевых клеток при влиянии биомассы хлореллы, подвергшейся разным способам дезинтеграции:

ВГ- высокоскоростной гомогенизатор, УЗВ - ультразвуковое воздействие; СВЧ - микроволновая дезинтеграция 
Показатель был найден для двух возрастных групп в каждой популяции: для молодых и основных клеток. Отношение площади поверхности к ее объему при добавлении биомассы хлореллы имеет тенденцию к снижению, наиболее существенное снижение наблюдается в варианте, где биомасса подвергалась СВЧдезинтеграции. Интенсификация почкования приводит к быстрому репликативному старению клеток в популяции, что связано с изменением формы клеток.

Выводы. Биомасса C. sorokiniana (количество вносимой биомассы 20 мг на 100 мл питательной среды), подвергшаяся предварительно СВЧ-дезентеграции, усиливает бродильную активность дрожжей. При этом увеличивается спиртообразующая способность дрожжей (на $43,5 \%$ и и видимая степень сбраживания (на $39,2 \%$ ), интенсивность почкования (количество дрожжевых клеток в популяции увеличивается на 31,0 \%) по сравнению с вариантом без добавления биомассы. Ультразвуковая и механическая дезинтеграции биомассы микроводоросли менее эффрективны для активирования S. cerevisiae.

Проблема регулирования метаболических процессов дрожжей на бродильных производствах остается актуальной, поэтому ведется поиск дешевых, эффрективных натуральных препаратов, позволяющих интенсифицировать процессы брожения и улучшить качество готовой продукции. Использование микроводорослей сопряжено с решением проблемы повышения биодоступности ценных компонентов из них и использование их в качестве стимуляторов жизненной активности дрожжей.

\section{Литература}

1. Пермякова Л.В. Классификация стимуляторов жизненной активности дрожжей // Техника и технология пищевых производств. 2016. - № 3 (42). - C. 46-55.

2. Пермякова Л.В. Совершенствование технологии получения пива путем предварительной подготовки дрожжей // Инновации в пищевой биотехнологии: сб. тр. междунар. симпозиума / под общ. ред. А.Ю. Просекова. - Кемерово, 2018. - С. 486-489.

3. Пат. РФ № 2145351 С1. Способ активации дрожжей / Гернет М.В., Лаврова В.Л., Кор- неев А.Д., Лямин М.Я., Зайцев С.И., Кузнецова Л.В., Иванов А.А., Воробьева В.В. Заявл. 24.08.1999; опубл. 10.02.2000.

4. Сафрина Д.Р., Халимов М.Н., Турсунов Ф.Р., Решетник О.А. Способы повышения бродильной активности хлебопекарных дрожжей // Integral. - 2019. - № 1. - C. 94-119.

5. Patras D., Moraru C.V., Socaciu C. Screening of bioactive compounds synthesized by microalgae: a progress overview on extraction and chemical analysis // Studia UBB chemia. 2018. - LXIII, 1. - Pp. 21-35.

6. Jaeschke D.P., Rech R., Ferreira Marczak L.D., Mercali G.D. Ultrasound as an alternative technology to extract carotenoids and lipids from Heterochlorella luteoviridis // Bioresource Technology. - 2017. - 224. - Pp. 753-757.

7. Lizzul A. M., Lekuona-Amundarain A., Purton S. and Campos L.C. Characterization of Chlorella sorokiniana, UTEX 1230 / Alessandro Marco Lizzul, Aitor Lekuona-Amundarain, Saul Purton and Luiza Cintra Campos // Biology. 2018. - № 7. - Pp. 1-25.

8. Bazarnova Y., Kuznetsova T., Boysen H.E. Methods for concentrating the cell suspension of chlorella microalgae for obtaining pigment complex // International Journal of Civil Engineering and Technology. - 2018. - T. 9, № 10. - C. 340-350.

9. Состав хлореллы. - URL: http://algobiotehnologia. $\mathrm{com} / \mathrm{shop} /$ ?gid=98.

10. Меледина Т.В., Давыденко С.Г. Дрожжи Saccharomyces cerevisiae. Морфология, химический состав, метаболизм: учеб. пособие. - СПб., 2015. - 88 с.

11. Udeh H.O., Kgatla T.E. Role of magnesium ions on yeast performance during very high gravity fermentation // Journal of Brewing and Distilling. - 2017. - Vol. 4(2). - Pp. 19-45.

12. Патент на изобретение RUS. 2668162 Способ культивирования микроводоросли Chlorella / Политаева Н.А., Базарнова Ю.Г., Смятская Ю.А., Кузнецова Т.А., Трухина Е.В. - Опубл. 06.12.2017.

13. Базарнова Ю.Г., Кузнецова Т.А., Смятская Ю.А. Способ получения пигментного комплекса из биомассы одноклеточных водорослей рода Chlorella: патент на изобретение РФ. 2695879. - Опубл. 29.07.2019.

14. Кузнецова Т.А., Иванченко О.Б., Калинкин Н.С. Влияние компонентов шиповника на морфофиизиологическое состояние кле- 
ток дрожжей // Международный научноисследовательский журнал. - 2017. - № 8-2 (62). - C. 16-20.

15. Боргоякова А.С., Кузнецова Т.А. Морфофиизиологическая оценка стрессовых реакций клеток Saccharomyces cerevisiae на токсическое влияние спирта // Неделя науки СПбПУ: мат-лы науч. конф. с междунар. участием. - СПб., 2017. - С. 8-10.

16. Моргунова Е.М., Нефёдов Л.И., Назарова Ю.С. Влияние микроскопической водоросли хлореллы на интенсивность роста дрожжей Saccharomyces cerevisiae // Пищевая промышленность: наука и технологии. 2013. - № 4 (22). - C. 65-69.

\section{Literatura}

1. Permyakova L.V. Klassifikaciya stimulyatorov zhiznennoj aktivnosti drozhzhej // Tekhnika i tekhnologiya pishchevyh proizvodstv. 2016. - № 3 (42). - S. 46-55.

2. Permyakova L.V. Sovershenstvovanie tekhnologii polucheniya piva putem predvaritel'noj podgotovki drozhzhej // Innovacii v pishchevoj biotekhnologii: sb. tr. mezhdunar. Simpoziuma / pod obshch. red. A.Yu. Prosekova. Kemerovo, 2018. - S. 486-489.

3. Pat. RF № 2145351 C1. Sposob aktivacii drozhzhej / Gernet M.V., Lavrova V.L., Korneev A.D., Lyamin M.YA., Zajcev S.I., Kuznecova L.V., Ivanov A.A., Vorob'eva V.V. Zayavl. 24.08.1999; opubl. 10.02.2000.

4. Safina D.R., Halimov M.N., Tursunov F.R., Reshetnik O.A. Sposoby povysheniya brodil'noj aktivnosti hlebopekarnyh drozhzhej // Integral. - 2019. - № 1. - S. 94-119.

5. Patras D., Moraru C.V., Socaciu C. Screening of bioactive compounds synthesized by microalgae: a progress overview on extraction and chemical analysis // Studia UBB chemia. 2018. - LXIII, 1. - Pp. 21-35.

6. Jaeschke D.P., Rech R., Ferreira Marczak L.D., Mercali G.D. Ultrasound as an alterna-tive technology to extract carotenoids and lipids from Heterochlorella luteoviridis /I Biore-source Technology. - 2017. - 224. - Rr. 753-757.

7. Lizzul A. M., Lekuona-Amundarain A., Purton S. and Campos L.C. Characterization of Chlorella sorokiniana, UTEX 1230 / Alessandro Marco Lizzul, Aitor Lekuona-Amundarain, Saul Purton and Luiza Cintra Campos // Biology. - 2018. № 7. - Pp. 1-25.

8. Bazarnova Y., Kuznetsova T., Boysen H.E. Methods for concentrating the cell suspension of shlorella microalgae for obtaining pigment complex // International Journal of Civil Engineering and Technology. - 2018. - T. 9, № 10. - S. 340-350.

9. Sostav hlorelly. - URL: http://algobiotehnologia .com/shop/?gid=98.

10. Meledina T.V., Davydenko S.G. Drozhzhi Saccharomyces cerevisiae. Morfologiya, himicheskij sostav, metabolizm: ucheb. posobie. - SPb., 2015. - $88 \mathrm{~s}$.

11. Udeh H.O., Kgatla T.E. Role of magnesium ions on yeast performance during very high gravity fermentation // Journal of Brewing and Distilling. - 2017. - Vol. 4(2). - Pp. 19-45.

12. Patent na izobretenie RUS. 2668162 Sposob kul'tivirovaniya mikro-vodorosli Chlorella / Politaeva N.A., Bazarnova YU.G., Smyatskaya Yu.A., Kuznecova T.A., Truhina E.V. Opubl. 06.12.2017

13. Bazarnova Yu.G., Kuznecova T.A., Smyatskaya Yu.A. Sposob polucheniya pigmentnogo kompleksa iz biomassy odnokletochnyh vodoroslej roda Chlorella: patent na izobretenie RF. 2695879. Opubl. 29.07.2019.

14. Kuznecova T.A., Ivanchenko O.B., Kalinkin N.S. Vliyanie komponentov shipovnika na morfofiziologicheskoe sostoyanie kletok drozhzhej // Mezhdunarodnyj nauchnoissledovatel'skij zhurnal. - 2017. - № 8-2 (62). - S. 16-20.

15. Borgoyakova A.S., Kuznecova T.A. Morfofiziologicheskaya ocenka stressovyh reakcij kletok Saccharomyces cerevisiae na toksicheskoe vliyanie spirta // Nedelya nauki SPbPU: mat-ly nauch. konf. s mezhdunar. uchastiem. - SPb., 2017. - S. 8-10.

16. Morgunova E.M., Nefyodov L.I., Nazarova Yu.S. Vliyanie mikroskopicheskoj vodorosli hlorelly na intensivnost' rosta drozhzhej Saccharomyces cerevisiae // Pishchevaya promyshlennost': nauka i tekhnologii. - 2013. № 4 (22). - S. 65-69. 